\title{
REVISTAMATĒRIA
}

ISSN 1517-7076 artigo e-11904, 2017

\section{Avaliação de inibidores de corrosão para estruturas de concreto armado}

\section{Evaluation of corrosion inhibitors for reinforced concrete structures}

César Augusto Trevisol ${ }^{1}$, Paulo Roberto Paes da Silva ${ }^{1}$, Marcos Marques da Silva Paula ${ }^{2}$, Fernando Pelisser ${ }^{3}$

\footnotetext{
${ }^{1}$ Universidade do Extremo Sul Catarinense, Criciúma. e-mail: cesartrevisol@gmail.com; paulorpaes@gmail.com

${ }^{2}$ Universidade do Sul de Santa Catarina, Campus Tubarão. e-mail: bocaocao@gmail.com

${ }^{3}$ Universidade Federal de Santa Catarina, Campus Florianópolis. e-mail: pelisser@hotmail.com
}

\section{RESUMO}

A corrosão de armadura é um dos maiores problemas que reduzem a durabilidade das estruturas de concreto, causada, frequentemente, pelo processo de carbonatação e ataque de íons cloretos, presentes em ambientes agressivos e marinhos. Estima-se que $90 \%$ dos problemas patológicos em estruturas de concreto no mundo tem como consequência a corrosão de armadura. Dessa forma, a pesquisa por materiais com resistência a este processo de deterioração é fundamental para melhorar a durabilidade e a eficiência das estruturas de concreto. Neste contexto, foi estudado o efeito de três aditivos químicos, um comercial à base de sais de nitrito, o molibdato de sódio $\left(\mathrm{MoNa}_{2} \mathrm{O}_{4}\right)$ e o tungstato de sódio $\left(\mathrm{Na}_{2} \mathrm{O}_{4} \mathrm{~W} .2 \mathrm{H}_{2} \mathrm{O}\right)$, utilizados nos teores de $1 \%$ e $2 \%$ em relação à massa de cimento. Foram preparados corpos de prova cilíndricos de argamassa (classe de resistência de $30 \mathrm{MPa}$ ) com aço embebidos neste, para serem submetidos ao ensaio eletroquímico de polarização potenciodinâmica. A utilização do aditivo comercial não foi eficiente na redução das taxas de corrosão, porém, o efeito do tempo de cura, reduziu a taxa média de corrosão de 4,7 mm/ano aos 60 dias, para 1,6 $\mathrm{mm} /$ ano, aos 90 dias. Os melhores resultados foram obtidos para os aditivos de molibdato e tungstato, nos quais foi observado um índice de eficiência do aditivo de 50\%, para adição de $1 \%$ de molibdato, e de $29 \%$, para adição de $2 \%$ de tungstato.

Palavras-chave: Corrosão, Concreto armado, Aditivos químicos.

\section{ABSTRACT}

Concrete reinforcement corrosion is one of the most important problems that diminish the durability of concrete structures, and it is often caused by the carbonation process and chloride ion attack in aggressive and marine environments. It is estimated that $90 \%$ of pathological problems affecting concrete structures worldwide lead to reinforcement corrosion. The research for materials with resistance to this deterioration process is fundamental to improve the durability and efficiency of concrete structures. In this context, the effect of three chemical additives, a commercial one based on nitrite salts, sodium molybdate $\left(\mathrm{MoNa}_{2} \mathrm{O}_{4}\right)$ and sodium tungstate $\left(\mathrm{Na}_{2} \mathrm{O}_{4} \mathrm{~W} .2 \mathrm{H}_{2} \mathrm{O}\right)$, used in contents of $1 \%$ and $2 \%$ in relation to the cement mass. Cylindrical, steel embedded, mortar samples (30 MPa strength class) were submitted to the potentiodynamic polarization test. The use of commercial additive was not efficient in reducing corrosion rates, but the effect of curing time reduced the mean corrosion rate from $4.7 \mathrm{~mm} /$ year at 60 days to $1.6 \mathrm{~mm} /$ year, at 90 days. The best results were obtained for the tungstate and molybdate additives, in which the addition of $1 \%$ of molybdate additive presented an efficiency rate of $50 \%$, while $2 \%$ of tungstate additive presented an efficiency rate of $29 \%$.

Keywords: Corrosion, Steel reinforced concrete; Chemical additives. 


\section{INTRODUÇÃO}

A corrosão de armadura em concreto armado através do ingresso de íons cloreto é uma das formas mais comuns, e com elevada incidência de degradação das estruturas, levando à redução de sua vida útil em ambientes agressivos. A recuperação dos danos relacionados às estruturas situadas em atmosfera altamente agressiva, ou em ambientes marinhos, gera um custo elevado. Neste sentido, quando o assunto é durabilidade, o tema desperta interesse dos pesquisadores, que, motivados pela frequente ocorrência de casos patológicos e custos elevados associados a esta recuperação, buscam o desenvolvimento de novas e eficientes técnicas de proteção.

As maiores cidades e centros urbanos do mundo estão situados na extensa região litorânea, onde, consequentemente, situam-se as maiores concentrações demográficas e edificações, que, com frequência, apresentam problemas patológicos, devido à corrosão do aço imerso no concreto. Esse problema é ocasionado, muitas vezes, pela falta de manutenção e poderia ser evitado utilizando materiais mais eficientes ou um sistema de proteção para a estrutura.

Dos sistemas de proteção existentes, merece destaque a utilização de aditivos químicos inibidores de corrosão adicionados na mistura do concreto, devido à facilidade de aplicação e custo relativamente baixo. Pesquisas existentes utilizam com eficiência à técnica quantitativa de resistência a polarização linear para mensurar a velocidade de corrosão no sistema aço/concreto [1], utilizando adições minerais [2], ou adicionando aditivos químicos inibidores de corrosão [3-8], porém, na maioria das vezes, o efeito dos aditivos químicos é avaliado em solução em contato com o aço [3-8], inferindo assim seu comportamento benéfico quando aplicado no concreto armado. No entanto, a medida de seu desempenho quando adicionado ao cimento ou concreto com aço embebido é testado com menor frequência utilizando o ensaio eletroquímico de polarização potenciodinâmica.

Neste contexto, considerando os resultados satisfatórios obtidos para Tang, Zhang e Zuo [5], utilizando os inibidores químicos de tungstato de sódio e molibdato de sódio - dentre outros -, que atingiram um índice de eficiência de $95 \%$ (para o molibdato de sódio) quando testado o aditivo em solução em contato direto com o aço (composição química - \% em peso: C 0,37, S 0,053, P 0,026, Si 0,16, Mn 0,32, Cr 10,9, Fe restante) [5] e o reduzido número de trabalhos no Brasil que quantificaram os índices de corrosão utilizando aditivos químicos inibidores, nesta pesquisa foram selecionados três aditivos inibidores, um comercial (à base de sais de nitrito), o molibdato de sódio e tungstato de sódio, para serem testados no sistema aço/concreto através de ensaios eletroquímicos.

\section{MATERIAIS E MÉTODOS}

Neste trabalho foram avaliados o efeito dos aditivos químicos contendo sais de nitrito (informado pelo fabricante, com $34 \%$ de sólidos e denominado de aditivo comercial), e os aditivos de molibdato de sódio (Mo$\left.\mathrm{Na}_{2} \mathrm{O}_{4}\right)$ e o tungstato de sódio $\left(\mathrm{Na}_{2} \mathrm{O}_{4} \mathrm{~W} \cdot 2 \mathrm{H}_{2} \mathrm{O}\right)$. O aditivo comercial (C) foi utilizado nas proporções de $20 \mathrm{e}$ $30 \mathrm{~L} / \mathrm{m}^{3}$ (conforme recomendação do fabricante) e o molibdato de sódio (M) e tungstato de sódio (T) foram utilizados nos percentuais de $1 \%$ e $2 \%$ em relação à massa de cimento (consumo de cimento da composição igual a $527 \mathrm{~kg} / \mathrm{m}^{3}$ ). O cimento utilizado foi o CP-V ARI RS.

Para confecção das amostras foi utilizada uma composição padrão de argamassa na proporção de 1:3:0,55 (cimento:areia:água/cimento(a/c) - em massa). As variáveis da pesquisa foram o tipo de aditivo, sua concentração e a idade de cura (tempo de imersão das amostras para hidratação do cimento). Os corpos de prova de argamassa foram produzidos com $\Phi=5 \mathrm{~cm} \times 10 \mathrm{~cm}$ de altura com uma barra de aço de $8 \mathrm{~mm}$ embebida na argamassa - conforme mostrado no esquema da figura 1 - para ser submetido ao ensaio eletroquímico. Para o preparo das amostras e as condições de ensaio foi adotada a metodologia descrita por Bignozzi e Bondua [9] e ASTM C 876 [10]. 


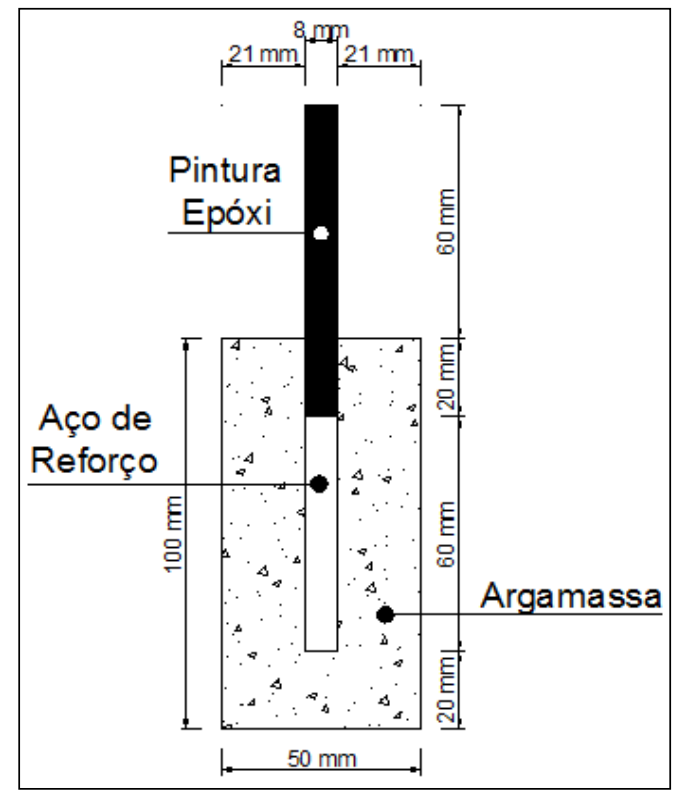

Figura 1: Esquema do corpo de prova de argamassa com barra metálica.

A limpeza das barras (aço tipo CA-50) foi realizada conforme descrito na norma ASTM G1 [11] através das seguintes etapas: $i$ ) imersão das barras por $10 \mathrm{~min}$, em solução preparada a partir da dissolução de $500 \mathrm{~mL}$ de ácido clorídrico e 3,5g de hexametilenotetramina em $1 \mathrm{~L}$ de água; ii) lavagem em água corrente e escovação das barras para retirada das impurezas restantes; iii) banho das barras em acetona; iv) secagem final das barras com ar quente; v) pintura com tinta epóxi comercial à base de alcatrão de hulha (utilizado duas demãos, segundo recomendações do fabricante, assegurando uma espessura de $0,5 \mathrm{~mm}$, com rendimento de $2,0 \mathrm{~m}^{2} / \mathrm{L}$ ). A barra com suporte para ser inserida no corpo de prova pode ser observada na figura 2 .

Ensaios eletroquímicos foram realizados com auxílio de um potenciostato/galvanostato (BioLogic, SP-200). Ensaios de polarização potenciodinâmica foram efetuados numa célula eletroquímica de três eletrodos. Como eletrodo de referência (ER) utilizou-se um eletrodo de calomelano saturado (SCE) em um capilar de Luggin contendo uma solução saturada de $\mathrm{KCl}[1,11]$. Uma malha de aço inoxidável AISI 310 foi usada como contra eletrodo (CE) e o aço embebido na argamassa como eletrodo de trabalho (ET). O aço (tipo CA50) nas amostras ficou com uma área de exposição de $15,57 \mathrm{~cm}^{2}$ que não recebeu pintura epóxi. O ensaio foi realizado a temperatura ambiente. A figura 3 ilustra o esquema da célula eletroquímica e a célula já montada para o experimento. Na Tabela 1 são mostrados os parâmetros eletroquímicos empregados no ensaio.

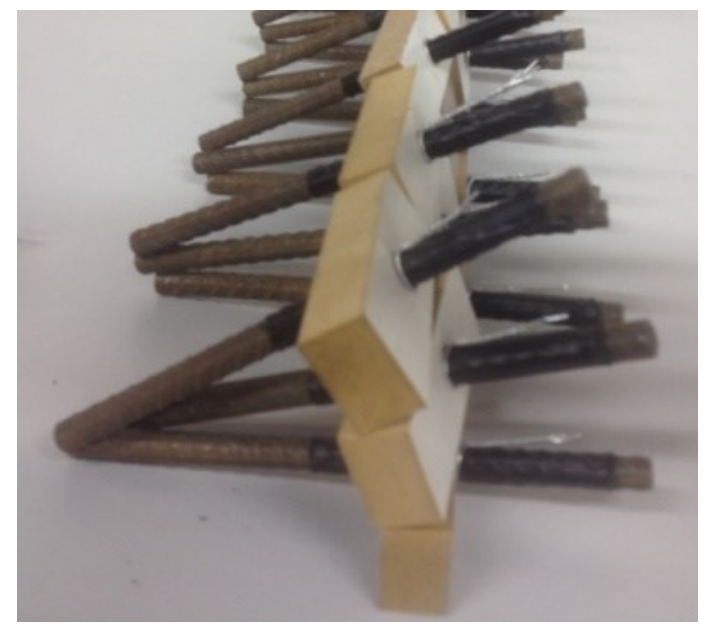

Figura 2: Barra de aço (aço tipo CA-50) preparadas e no suporte para serem embebidas na argamassa. 


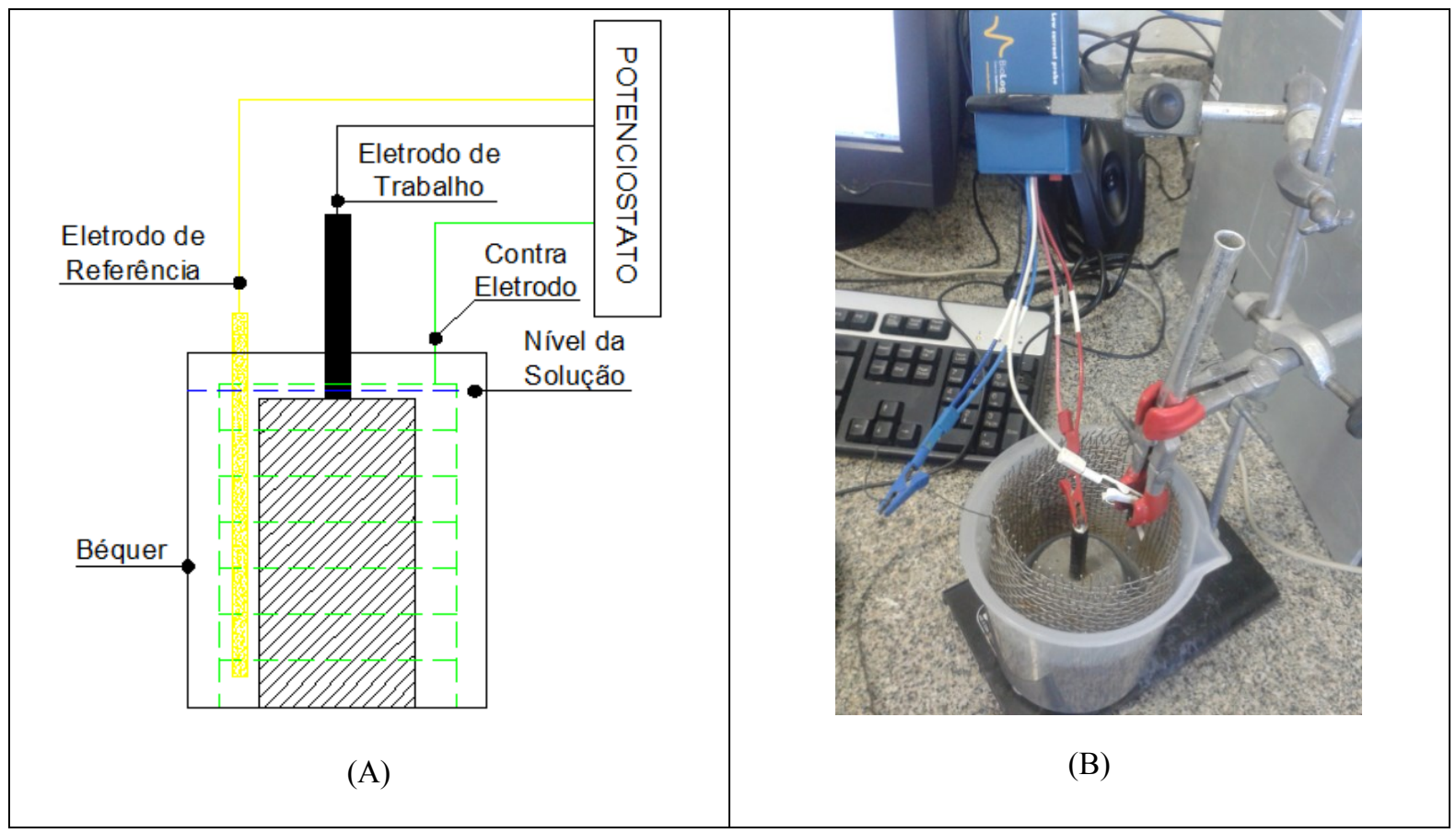

Figura 3: Desenho esquemático da célula eletroquímica (A) e da célula pronta para o ensaio (B).

Tabela 1: Parâmetros eletroquímicos empregados nos ensaios de polarização potenciodinâmica.

\begin{tabular}{lcc}
\hline \multicolumn{1}{c}{ Parâmetro } & Valor & Unidade \\
\hline Área do eletrodo de trabalho: & 15,574 & $\mathrm{~cm}^{2}$ \\
Eletrodo de referência (SCE) & 0,241 & $\mathrm{~V}$ \\
Peso equivalente do aço & 27,925 & $\mathrm{~g} / \mathrm{eq}$. \\
Densidade do aço & 7,850 & $\mathrm{~g} / \mathrm{cm}^{3}$ \\
E $_{\text {inicial }}$ & $-6,0$ & $\mathrm{~V}$ \\
E $_{\text {final }}$ & $+6,0$ & $\mathrm{~V}$ \\
Velocidade de variação do potencial & 10,0 & $\mathrm{mV} / \mathrm{s}$ \\
(dE/dt) & & 1200 \\
Tempo & & $\mathrm{s}$ \\
\hline
\end{tabular}

Antes da realização do ensaio as amostras foram imersas em uma solução de $\mathrm{NaCl}$ a 3,5\% (em massas), com imersão de $1 / 3$ de sua altura por 48 horas e imersão total 24 horas antes do ensaio. Para análise dos resultados de resistência à corrosão foi utilizado o software EC-Lab V10.23 e para análise estatística dos resultados, o software STATISTICA 7.0.

Para determinar à resistência a compressão axial (aos 28 dias de cura), foi adotado o seguinte procedimento: $i$ ) as faces dos corpos de prova foram regularizadas com pasta de cimento; ii) a carga foi aplicada continuamente, com velocidade de carregamento entre $0,3 \mathrm{MPa} / \mathrm{s}$ a $0,8 \mathrm{MPa} / \mathrm{s}$, utilizando uma prensa universal (fabricante EMIC), com controle de deslocamento e uma célula de carga com capacidade máxima de 20 ton.

Na tabela 2 podem ser observados os percentuais dos diferentes aditivos utilizados e a idade das amostras testadas. Em função dos resultados com maior variabilidade, obtidos aos 60 dias, para o aditivo comercial, e, considerando o tempo para conclusão da pesquisa, na segunda etapa, optou-se, pela idade única de 75 dias. 
Tabela 2: Resumo das composições utilizadas e idade do ensaio.

\begin{tabular}{|c|c|c|c|c|c|c|c|c|}
\hline \multirow{3}{*}{$\begin{array}{l}\text { Nome } \\
\text { REF }\end{array}$} & \multirow{3}{*}{$\begin{array}{c}\text { Aditivo } \\
-\end{array}$} & \multirow{3}{*}{$\begin{array}{c}\text { Concentração } \\
0\end{array}$} & \multicolumn{6}{|c|}{ Idade (dias) } \\
\hline & & & \multicolumn{2}{|c|}{60} & \multicolumn{2}{|c|}{75} & \multicolumn{2}{|c|}{90} \\
\hline & & & $\mathrm{A}$ & B & - & - & $\mathrm{A}$ & B \\
\hline $\mathrm{C} 20$ & \multirow{2}{*}{ Comercial } & $20 \mathrm{~L} / \mathrm{m}^{3}$ & A & B & - & - & $\mathrm{A}$ & $\mathrm{B}$ \\
\hline $\mathrm{C} 30$ & & $30 \mathrm{~L} / \mathrm{m}^{3}$ & A & $\mathrm{B}$ & - & - & $\mathrm{A}$ & $\mathrm{B}$ \\
\hline REF & - & 0 & - & - & A & B & - & - \\
\hline M1 & \multirow{2}{*}{ Tungstato } & $1 \%$ & - & - & A & B & - & - \\
\hline M2 & & $2 \%$ & - & - & A & $\mathrm{B}$ & - & - \\
\hline $\mathrm{T} 1$ & \multirow{2}{*}{ Molibdato } & $1 \%$ & - & - & A & B & - & - \\
\hline $\mathrm{T} 2$ & & $2 \%$ & - & - & A & $\mathrm{B}$ & - & - \\
\hline
\end{tabular}

\section{RESULTADOS}

\subsection{Resistência à Compressão}

Nesta pesquisa foi utilizada uma composição única de argamassa, com resistência à compressão aproximada de $30 \mathrm{MPa}$ e relação água/cimento $(\mathrm{a} / \mathrm{c})$ de 0,55 , e quando aplicada em concreto, atende as recomendações da norma NBR 6118 [12] para durabilidade mínima em classe de agressividade ambiental III - ambiente marinho. A classe de agressividade mais elevada é IV, caracterizando um ambiente de respingos de maré, onde deve ser utilizada uma resistência mínima do concreto de $40 \mathrm{MPa}$ e uma relação a/c máxima de 0,45 [12].

Na tabela 3 podem ser observados os resultados dos ensaios de resistência à compressão. Nas composições da $1^{\text {a }}$ Fase foi observado um efeito significativo do aditivo (C30) no aumento da resistência à compressão. Análise estatística (ANOVA, com confiabilidade de 95\%) mostra um índice $\mathrm{p}=0,04433$. Porém, utilizando o teste de Duncan, REF e C20 são equivalentes. Considerando que a relação água/cimento da mistura foi corrigida, considerando a água presente no aditivo comercial, e, que foram realizadas apenas duas concentrações, estes resultados não podem ser conclusivos (para C30). No entanto, alguns aditivos inibidores de corrosão - contendo sais de nitrito, por exemplo - podem acelerar as reações de hidratação do cimento, dependendo da dosagem do aditivo e do tipo de cimento [3], justificando assim, o resultado de C30. O efeito dos aditivos de tungstato e de molibdato, reforçam este comportamento, que os aditivos não influenciaram na resistência à compressão ( $\mathrm{p}=0,428351$, para composições da $2^{\mathrm{a}}$ Fase), como pode ser observado na Figura 5. A variabilidade das amostras apresentadas na tabela 5, com desvio padrão aproximado de 3 , é considerado normal para este tipo de material. Este comportamento é característico de inibidores de corrosão [3] que não interferem na formação do silicato de cálcio hidratado (C-S-H), que é a fase aglomerante e que define a resistência mecânica dos produtos à base de cimento Portland.

Tabela 3: Resultados de resistência à compressão (em MPa)

\begin{tabular}{|c|c|c|c|c|}
\hline \multirow{2}{*}{ Nome } & \multirow{2}{*}{ Fase } & \multicolumn{2}{|c|}{ Amostras } & \multirow{2}{*}{ Média } \\
\hline & & 1 & 2 & \\
\hline REF & \multirow{3}{*}{ 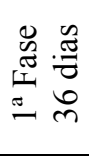 } & 20,8 & 23,2 & 22,0 \\
\hline $\mathrm{C} 20$ & & 22,2 & 19,5 & 20,8 \\
\hline $\mathrm{C} 30$ & & 27,1 & 29,7 & 28,4 \\
\hline REF & \multirow{5}{*}{ 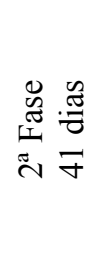 } & 33,0 & 32,0 & 32,5 \\
\hline M1 & & 32,2 & 36,9 & 34,6 \\
\hline M2 & & 33,3 & 29,4 & 31,4 \\
\hline $\mathrm{T} 1$ & & 34,6 & 32,5 & 33,6 \\
\hline $\mathrm{T} 2$ & & 35,0 & 35,6 & 35,3 \\
\hline
\end{tabular}




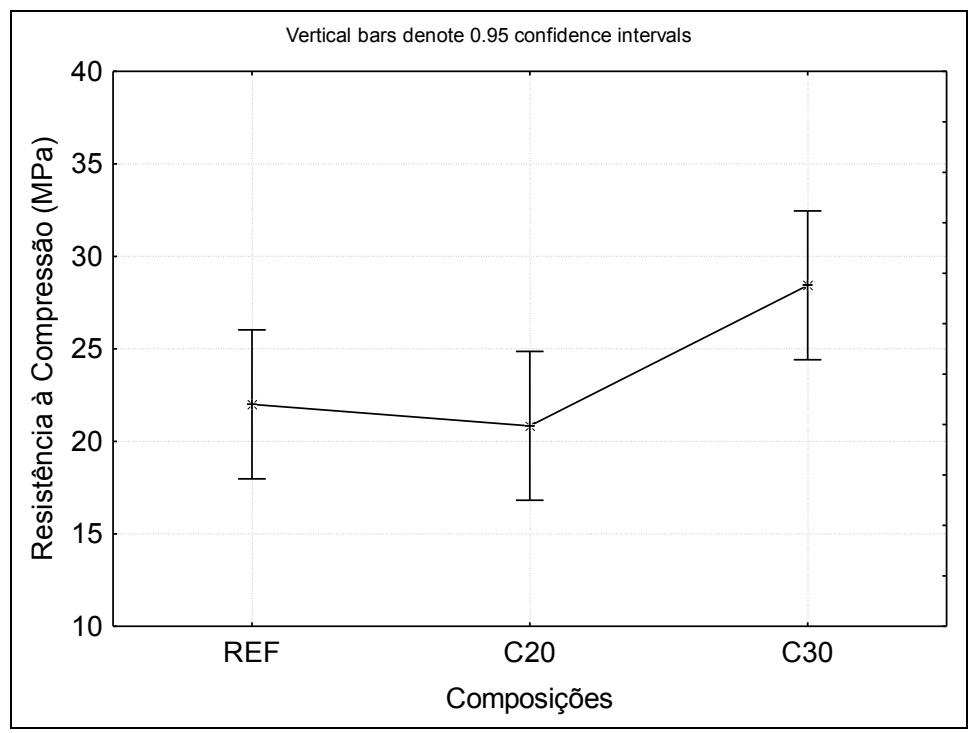

Figura 4: Resistência à compressão média das composições utilizando aditivo comercial.

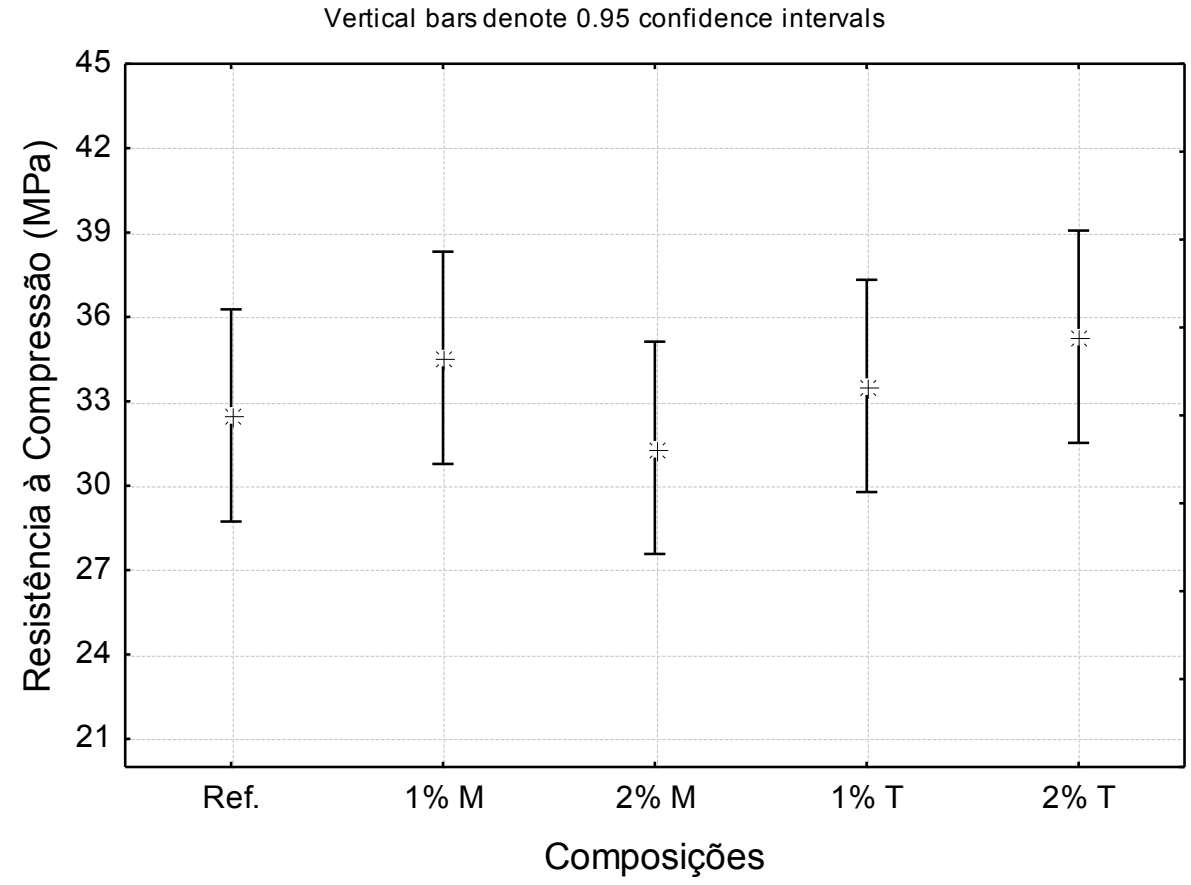

Figura 5: Resistência à compressão média das composições utilizando os inibidores T e M.

\subsection{Efeito dos Aditivos Inibidores na Resistência à Corrosão}

\subsubsection{Aditivo Comercial}

Após 28 dias de cura imersa e as amostras terem atingido a idade de 60 e 90 dias, foram realizados os ensaios de polarização potenciodinâmica. As taxas de corrosão foram calculadas a partir das inclinações de Tafel. As curvas de polarização potenciodinâmicas para as amostras contendo aditivo comercial, registradas com $60 \mathrm{e}$ 90 dias de idade são apresentadas na figura 6. Observa-se que os perfis $E$ vs. $\log i$ para a região anódica são típicos de processos redox regidos por ativação, já que a reação limitante do processo corrosivo é a reação catódica.

$\mathrm{Na}$ região de potencial catódico observa-se que em $\mathrm{E}=1,60 \mathrm{~V}$ há um indicativo de início de formação de filme de passivação, que pode ser constatado com a diminuição da densidade de corrente. Contudo, este filme não é estável o suficiente para promover uma adequada proteção neste potencial. A densidade de corrente volta a crescer quando o potencial atinge $1,90 \mathrm{~V}$, caminhando em direção a transpassivação do metal, 
isto é, a dissolução do mesmo.

As taxas de corrosão foram calculadas a partir das inclinações de Tafel, cujos valores de $\beta_{\mathrm{a}}$ e $\beta_{\mathrm{c}}$ são apresentados na Tabela 4, junto com os demais resultados eletroquímicos, isto é, potencial de corrosão ( $\left.\mathrm{E}_{\text {corr }}\right)$, densidade de corrente de corrosão $\left(\mathrm{I}_{\text {corr }}\right)$, taxa de corrosão. Os valores apresentados são os valores médios obtidos a partir de dois ensaios de corrosão para cada composição.

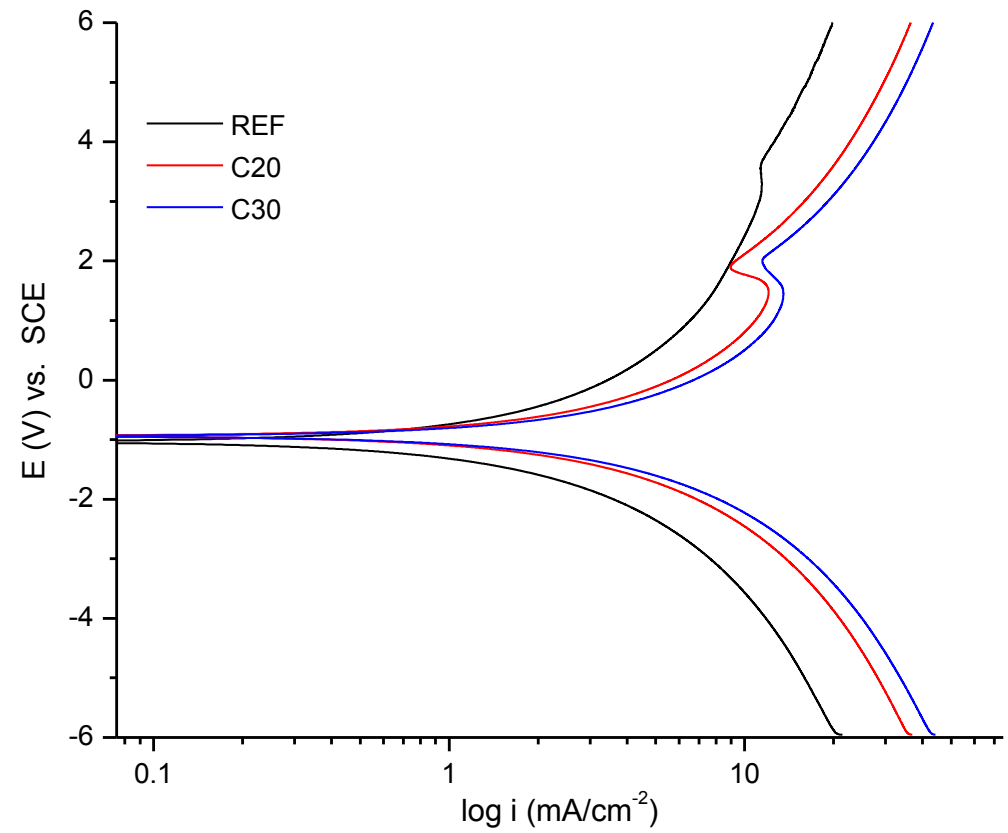

(A)

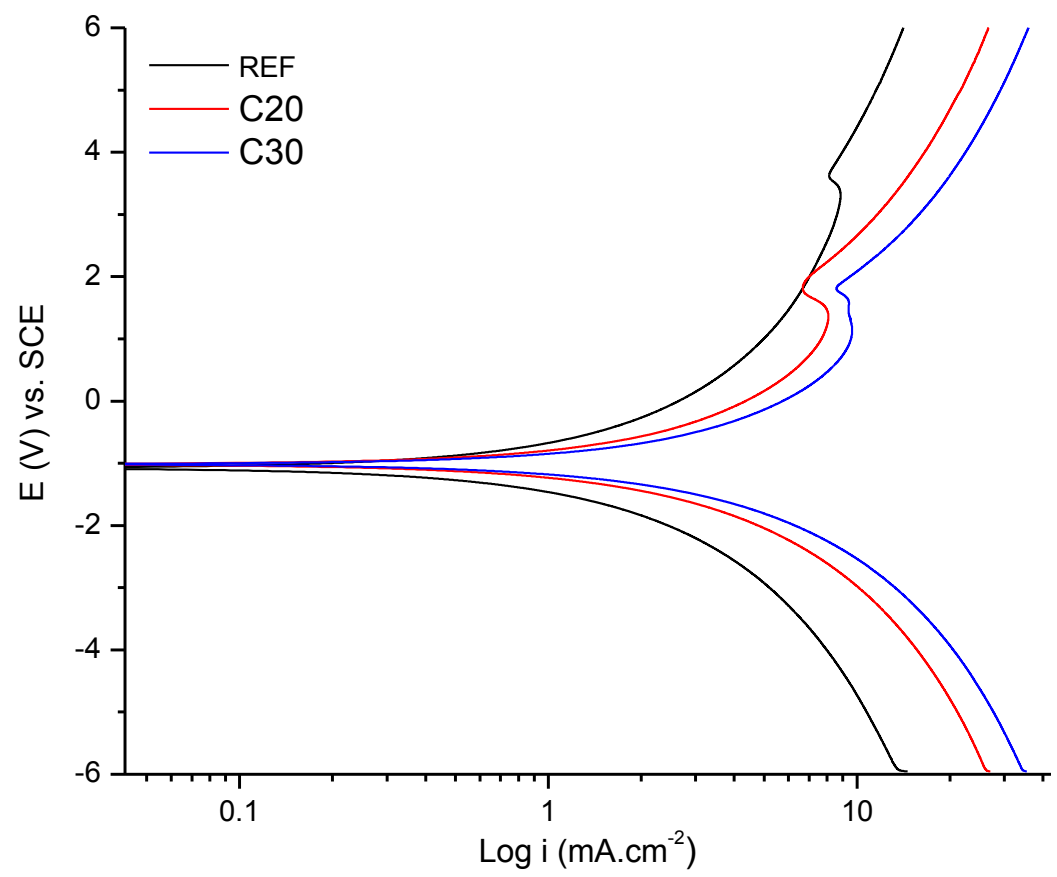

Figura 6: Curvas de polarização para inibidor comercial aos 60 dias (A) e aos 90 dias (B). 
Tabela 4: Resultados dos ensaios de polarização potenciodinâmica para o aditivo comercial após 60 e 90 dias de cura.

\begin{tabular}{ccccccc}
\hline & \multicolumn{7}{c}{ Idade da Amostra (dias) } \\
\cline { 2 - 7 } & $\mathbf{R E F}$ & $\mathbf{C 2 0}$ & $\mathbf{C 3 0}$ & $\mathbf{R E F}$ & $\mathbf{C 2 0}$ & $\mathbf{C 3 0}$ \\
\cline { 2 - 7 } $\mathbf{E}_{\mathbf{c o r r}}(\mathbf{V})$ & $-1,03$ & $-0,94$ & $-0,94$ & $-1,07$ & $-1,01$ & $-1,02$ \\
$\mathbf{I}_{\mathbf{c o r r}}\left(\mathbf{m A} / \mathbf{c m}^{2}\right)$ & 4,25 & 6,62 & 7,35 & 2,15 & 2,03 & 2,38 \\
$\boldsymbol{\beta a ~ ( m V ) ~}$ & $7.049,10$ & $5.134,30$ & $4.731,80$ & $4.221,70$ & $2.140,70$ & $1.856,00$ \\
$\boldsymbol{\beta c}(\mathbf{m V})$ & $4.701,10$ & $4.801,70$ & $4.458,10$ & $3.621,70$ & $2.053,20$ & $1.720,50$ \\
Taxa de corrosão & 3,17 & 5,45 & 5,49 & 1,60 & 1,52 & 1,78 \\
$(\mathbf{m m} / \mathbf{a n o})$ & & & & & & \\
\hline
\end{tabular}

Considerando os resultados da Tabela 4, percebe-se que houve um acréscimo na taxa de corrosão para ambas as composições (C20 e C30) aos 60 dias, quando comparados com a REF, isto é, sem aditivo. Para os ensaios realizados aos 90 dias, observa-se uma taxa de corrosão muito próxima entre as composições. Para a formulação de referência, a taxa foi de 1,60 mm/ano. Para as formulações C20 e C30, as taxas de corrosão foram de 1,52 e $1,78 \mathrm{~mm} /$ ano, respectivamente.

Estes resultados confirmam o comportamento observado nas curvas de polarização potenciodinâmicas, que indicam que a corrosão é bastante sensível e é influenciada pela umidade e temperatura, por exemplo [13]. Como os ensaios foram realizados em ambiente de laboratório, estas variáveis foram controladas. Porém a microestrutura do concreto, principalmente na interface aço-argamassa, pode ser considerada um fator de influência. Com o passar do tempo, aos 90 dias, a estrutura de cimento hidratado está mais coesa, causando maior proteção à passagem da corrente, o que explicaria a modificação do comportamento.

Ao realizar análise estatística (ANOVA), pode-se concluir que a variação da concentração do aditivo comercial não é significativa na redução das taxas de corrosão ( $\mathrm{p}=0,279395)$.

Heck [14] realizou um estudo para determinar a taxa de corrosão de amostras de aço carbono tipo

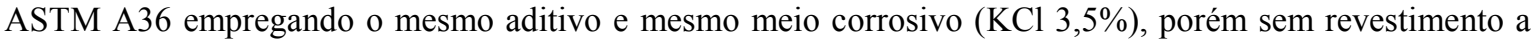
base de cimento. Foram utilizadas diferentes concentrações de aditivo, ou seja, 0, 1, 2, 2,5 e 3\%, em relação ao volume de solução (Tabela 5). Os resultados revelam que as taxas de corrosão são reduzidas drasticamente com a adição de inibidor, independente da concentração. A taxa de corrosão sem inibidor é de 2,603 mm/ano, ao passo que com a adição de apenas $1 \%$ de inibidor, a taxa de corrosão é de $0,383 \mathrm{~mm} / \mathrm{ano}$. Isto corresponde a uma eficiência de inibição de $85 \%$, que é um valor elevado. Considerando estes resultados, podemos observar a eficiência do inibidor na proteção do processo corrosivo do aço em meio salino. Porém, quando aplicado no aço embebido na argamassa, onde os fenômenos na interface entre o aço e o concreto são muito mais complexos do que uma interface metal-solução, a proteção não se verifica. Outros autores já verificaram o fraco desempenho dos aditivos de sais de nitrito em matrizes de cimento Portland [15].

Tabela 5: Taxas de corrosão estimadas para o aço ASTM A36 com aditivo inibidor comercial [14].

\begin{tabular}{cccc}
\hline Inibidor & $\mathrm{E}_{\text {corr }}(\mathrm{V})$ & $\begin{array}{c}\mathrm{I}_{\text {corr }} \\
\left(\mu \mathrm{A} / \mathrm{cm}^{2}\right)\end{array}$ & $\begin{array}{c}\text { Taxa de corrosão } \\
(\mathrm{mm} / \mathrm{ano})\end{array}$ \\
\hline $0 \%$ & $-1,103$ & 223,641 & 2,603 \\
\hline $1 \%$ & $-0,999$ & 32,915 & 0,383 \\
\hline $2 \%$ & $-0,985$ & 43,738 & 0,509 \\
\hline $2,5 \%$ & $-0,998$ & 33,667 & 0,391 \\
\hline $3 \%$ & $-0,968$ & 33,180 & 0,386 \\
\hline
\end{tabular}

Entretanto, considerando o efeito da idade nas taxas de corrosão, podemos verificar que o processo de hidratação, a idade ou a consolidação da pasta de cimento Portand é uma variável importante, que influencia nas taxas de corrosão do concreto armado exposto em ambiente salino. Neste caso, a taxa de corrosão para a amostra C20 após 90 dias é $72 \%$ menor em relação à taxa para a amostra C20 após 60 dias. Na Figura 7 pode ser observado o valor médio, de 4,7 mm/ano aos 60 dias e 1,6 mm/ano aos 90 dias. Esses resultados mostram a importância dos procedimentos de cura ou os cuidados que devem ser seguidos na construção das es- 
truturas, até que apresente resistência ou estabilidade necessária para resistir aos inúmeros esforços de origem física e química à quais são expostas.

Figura 7: Efeito da idade nas taxas de corrosão do concreto com inibidor comercial (valor médio).

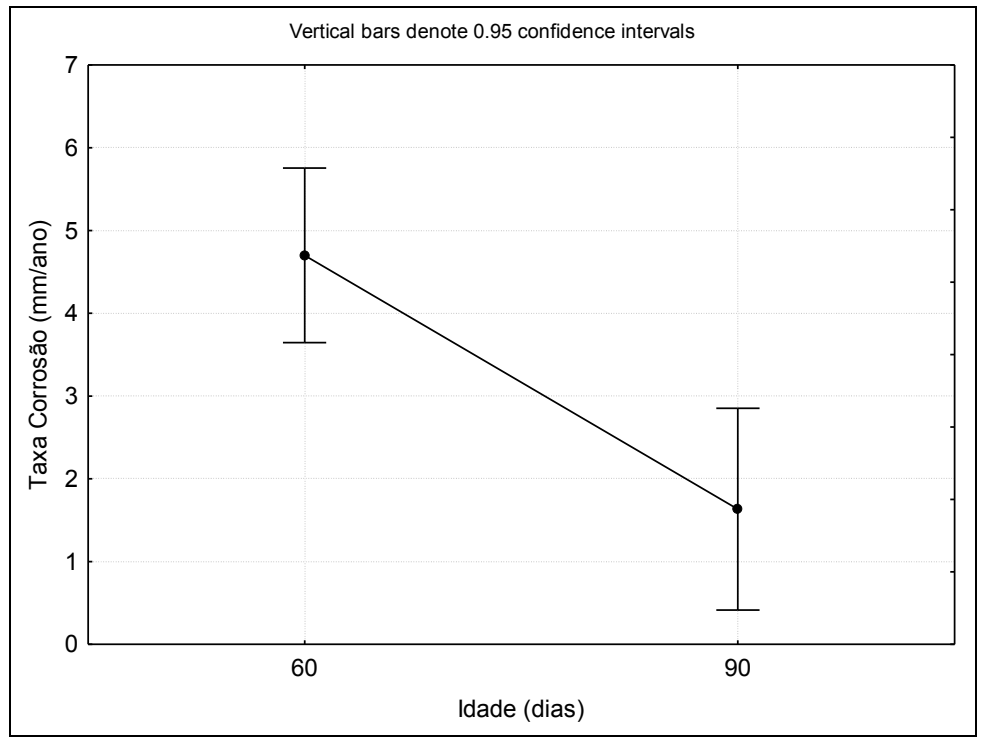

\subsubsection{Aditivos Inibidores de Molibdato e Tungstato}

Conforme dito anteriormente, optou-se por estudar o efeito do molibdato de sódio (M) e tungstato de sódio (T) na idade de 75 dias. As figuras $8 \mathrm{~A}$ e $8 \mathrm{~B}$ ilustram os traçados gráficos dos perfis $E v s$. $\log i$ para as amostras contendo molibdato de sódio e tungstato de sódio, respectivamente, para as concentrações de $1 \%$ e $2 \%$. 


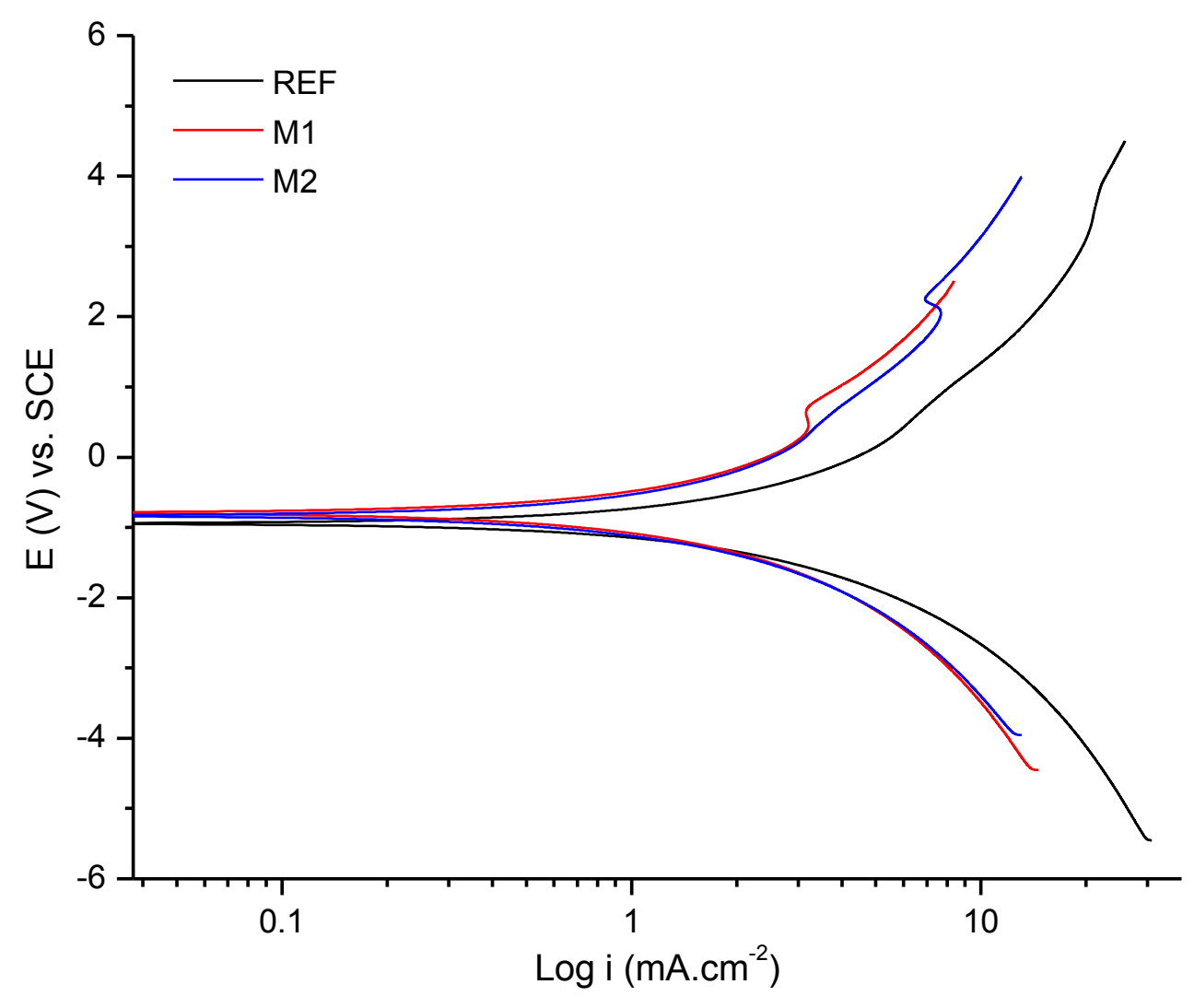

(A)

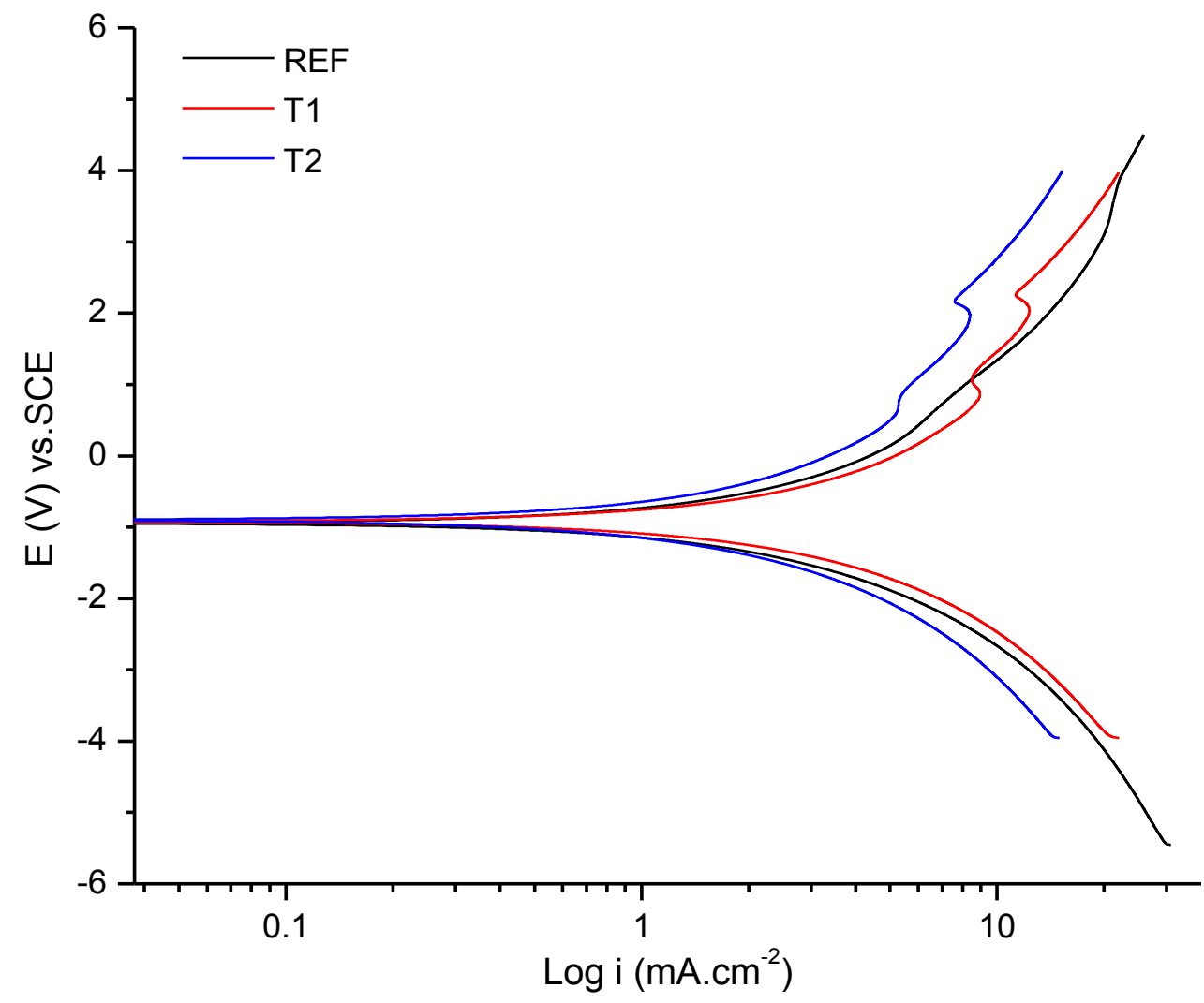

(B)

Figura 8: Curvas de polarização para o efeito do molibdato de sódio (A) e tungstato de sódio (B) nas concentrações de 1 e $2 \%$. 
A partir dos perfis potenciodinâmicos mostrados na Figura 8, calculou-se as inclinações de Tafel, os potenciais de corrosão $\left(\mathrm{E}_{\text {corr }}\right)$, as correntes de corrosão $\left(\mathrm{I}_{\text {corr }}\right)$, as taxas de corrosão e as eficiências de inibição dos aditivos, cujos valores são mostrados na Tabela 6 .

Tabela 6: Resultados dos ensaios de polarização potenciodinâmica para as adições de molibdato de sódio e tungstato de sódio, nas concentrações de 1 e $2 \%$.

\begin{tabular}{|c|c|c|c|c|c|c|}
\hline & \multicolumn{6}{|c|}{ Aditivo Inibidor } \\
\hline & \multicolumn{3}{|c|}{ Molibdato de sódio (\%) } & \multicolumn{3}{|c|}{ Tungstato de sódio (\%) } \\
\hline & $\mathbf{0}$ & 1 & 2 & $\mathbf{0}$ & 1 & 2 \\
\hline $\mathbf{E}_{\text {corr }}(\mathrm{V})$ & $-1,01$ & $-0,92$ & $-0,87$ & $-1,01$ & $-0,94$ & $-0,92$ \\
\hline$I_{\text {corr }}\left(\mathbf{m A} / \mathrm{cm}^{2}\right)$ & 2,98 & 1,50 & 1,72 & 2,98 & 4,04 & 2,13 \\
\hline$\beta \mathbf{a}(\mathbf{m V})$ & $3.168,60$ & $2.332,50$ & $2.609,40$ & $3.168,60$ & $3.512,10$ & $2.863,70$ \\
\hline$\beta c(m V)$ & $2.335,30$ & $2.149,30$ & $2.259,40$ & $2.335,30$ & $2.930,90$ & $2.356,60$ \\
\hline $\begin{array}{l}\text { Taxa de corrosão } \\
\text { (mm/ano) }\end{array}$ & 2,23 & 1,12 & 1,28 & 2,23 & 3,02 & 1,59 \\
\hline Eficiência média (\%) & - & 50 & 42 & - & -35 & 29 \\
\hline
\end{tabular}

Os resultados da Tabela 6 revelam que a máxima eficiência de inibição foi obtida empregando-se $1 \%$ de molibdato de sódio. Para $2 \%$ de adição, a eficiência é menor, ou seja, $42 \%$. Por outro lado, um comportamento inverso se verifica para o aditivo a base de tungstato de sódio. Para adição de $1 \%$, verifica-se na verdade, uma eficiência "negativa", o que corresponde a um aumento na taxa de corrosão. Contudo, a adição de $2 \%$ de aditivo reestabelece o efeito inibidor, que é de $29 \%$. Tal comportamento não é incomum de se verificar para sistemas contendo inibidores de corrosão. Isto indica que a um estudo minucioso do efeito da concentração de inibidor é fundamental para o sucesso na redução da taxa de corrosão.

Um estudo anterior demonstrou que os aditivos de tungstato e principalmente de molibdato, inibem a corrosão do aço com boa eficiência [5]. Contudo, neste estudo, os autores utilizaram um sistema aço - meio corrosivo, isto é, com corpos de prova não revestidos por cimento. Foi verificada uma redução das taxas de corrosão atingindo um índice de 98\% [5]. Considerando o efeito em argamassas, Rakanta et al. [16] ao estudar a ação inibidora do dimetilaminoetanol na proteção à corrosão de aço, verificaram a redução das taxas de corrosão em aproximadamente 50\%, ao empregarem uma concentração de $1 \%$ de aditivo. O uso de $2 \%$ de aditivo não mostrou aumento na ação inibidora.

Em pesquisa complementar [17] foi avaliado o efeito dos mesmos aditivos de tungstato e molibdato, porém em solução de $\mathrm{KCl} 3,5 \%$ colocado em contato direto com o aço. Foram adotadas as concentrações de $0,015 \%$ e $0,030 \%$ em volume. Os resultados apresentados na tabela 7 mostram uma eficiência entre $70 \%$ e $77 \%$ para o aditivo de molibdato e aproximadamente $55 \%$ para o aditivo de tungstato. Estes resultados são proporcionais ao seu efeito quando testado em aço embebido na argamassa, onde o aditivo de molibdato, mostrou-se mais eficiente. Os resultados também mostram uma redução média da eficiência de aproximadamente $40 \%$, quando aplicado no sistema aço/argamassa em relação ao aço.

Tabela 7: Taxas de corrosão estimadas para as adições de molibdato e tungstato em contato com o aço [17].

\begin{tabular}{cccccc}
\hline Nome & $\begin{array}{c}\text { Concentração } \\
(\%)\end{array}$ & $\mathrm{E}_{\text {corr }}(\mathrm{V})$ & $\begin{array}{c}\mathrm{I}_{\text {corr }} \\
\left(\mu \mathrm{A} / \mathrm{cm}^{2}\right)\end{array}$ & $\begin{array}{c}\text { Taxa } \\
(\mathrm{mm} / \mathrm{ano})\end{array}$ & $\begin{array}{c}\text { Eficiência } \\
\text { média de } \\
\text { inibição }(\%)\end{array}$ \\
\hline REF & 0 & $-1,001$ & 35,972 & 0,419 & - \\
\hline M1 & 0,015 & $-1,012$ & 11,009 & 0,128 & 70 \\
\hline M2 & 0,030 & $-1,032$ & 8,299 & 0,096 & 77 \\
\hline T1 & 0,015 & $-1,079$ & 16,939 & 0,197 & 53 \\
\hline T2 & 0,030 & $-1,064$ & 16,132 & 0,187 & 55 \\
\hline
\end{tabular}




\section{CONCLUSÕES}

Considerando o ensaio eletroquímico de polarização potenciodinâmica, a partir do qual foram calculadas as inclinações de Tafel, os potenciais de corrosão $\left(\mathrm{E}_{\text {corr }}\right)$, as correntes de corrosão $\left(\mathrm{I}_{\text {corr }}\right)$, as taxas de corrosão e as eficiências de inibição dos aditivos, pode-se concluir, que a máxima eficiência de inibição, atingindo $50 \%$, foi obtida empregando-se $1 \%$ de molibdato de sódio, sendo que para $2 \%$ de adição, a eficiência foi menor. Por outro lado, um comportamento inverso foi verificado para o tungstato de sódio. Para adição de $1 \%$, verifica-se uma eficiência "negativa" e para adição de $2 \%$, reestabelece o efeito inibidor, que é de $29 \%$. Tal comportamento não é incomum de se verificar para sistemas contendo inibidores de corrosão. Isto indica que um estudo minucioso do efeito da concentração de inibidor é fundamental para o sucesso na redução da taxa de corrosão.

O efeito do aditivo comercial, à base de sais de nitrito, não se mostrou efíciente. No entanto, ao analisar a curva do ensaio de polarização potenciodinâmica, foi verificado um comportamento diferenciado quando é utilizado o aditivo, mostrando um indicativo de início de formação de filme de passivação, porém, não estável o suficiente, para promover uma proteção, considerando os parâmetros do ensaio. Complementarmente, o efeito do tempo de cura (avaliado com o aditivo comercial), mostrou-se um fator significativo, pois provocou uma redução da taxa média de corrosão de 4,7 mm/ano aos 60 dias, para 1,6 mm/ano, aos 90 dias. Ao considerarmos os procedimentos de cura como um dos principais requisitos a serem controlados na execução das estruturas de concreto, pode-se concluir que é um cuidado fundamental para evitar a corrosão de armadura precoce e garantir sua durabilidade.

Neste trabalho, os aditivos químicos inibidores de corrosão, mostraram potencial para alterar a velocidade de corrosão em estruturas de concreto expostas a ambientes agressivos. Diante da incidência frequente deste tipo de problema patológico, da facilidade de aplicação do aditivo e seu custo competitivo, esse tipo de produto deve ser explorado a fim de assegurar maior vida útil das estruturas, que são cada vez mais arrojadas no projeto, frequentemente construídas em ambientes agressivos e cada vez mais exigidas quanto ao seu desempenho.

\section{AGRADECIMENTOS}

Os autores agradecem o Conselho Nacional de Desenvolvimento Científico e Tecnológico (CNPq).

\section{BIBLIOGRAFIA}

[1] ITTY, P-A., SERDAR, M., MERAL, C., et al.,"In situ 3D monitoring of corrosion on carbon steel and ferritic stainless steel embedded in cement paste”, Corrosion Science,v. 83, pp. 409-418, 2014.

[2] BASTIDAS, D.M., FERNANDEZ-JIMENEZ, A., PALOMO, A., et al.,"A study on the passive state stability of steel embedded in activated fly ash mortars", Corrosion Science, v. 50, pp. 1058-1065, 2008.

[3] SOYLEV, T.A., RICHARDSON, M.G., "Corrosion inhibitors for steel in concrete: State-of-the-art report"Construction and Building Materials, v. 22, pp. 609-622, 2008.

[4] SONG, G., STJOHN, D. "Corrosion behaviour of magnesium in ethylene glycol", Corrosion Science, v. 46, pp. 1381-1399, 2004.

[5] TANG, Y., ZHANG, G., ZUO, Y.,"The inhibition effects of several inhibitors on rebar in acidified concrete pore solution",Construction and Building Materials, v. 28, pp. 327-332, 2012.

[6] ABD, E.H.S.M., ABD, E.W.S., BAHGAT, A. "Environmental factors affecting the corrosion behaviour of reinforcing steel:VI Benzotriazole and its derivatives as corrosion inhibitors of steel",Corrosion Science, v. 87, pp. 321-333, 2014.

[7] QUA, Q., LI, L., BAI, W., et al., Sodium tungstate as a corrosion inhibitor of cold rolled steel in peracetic acid solution, Corrosion Science, v. 51, pp. 2423-2428, 2009.

[8] HELLSTROM, E.E. "A Preliminary Study of the Redox Behavior of Tungstate and Molybdate Ions in Na2SO4 at 1203 K”, Corrosion Science, v. 7, pp. 709-715, 1983.

[9] BIGNOZZI, M.C., BONDUÀ, S.,"Alternative blended cement with ceramic residues: Corrosion resistance investigation on reinforced mortar",Cement and Concrete Research, v. 41, pp. 947-954, 2011.

[10] AMERICAN STANDARD ASTM C876, Standard Test Method for Corrosion Potentials ofUncoated Reinforcing Steel in Concrete, American Society for Testing and Materials, West Conshoshockner, PA, USA, 2009.

[11] AMERICAN STANDARD ASTM G1, Standard Practice for Preparing, Cleaning, and Evaluating Cor- 
rosion Test Specimens. Philadelphia: Annual Book of ASTM Standards, 1999.

[12] ASSOCIAÇÃO BRASILEIRA DE NORMAS TÉCNICAS, ABNT NBR 6118, Projeto de Estruturas de Concreto, Rio de Janeiro, Brazil.

[13] RIBEIRO, D.V., Corrosão em Estruturas de Concreto Armado: Teoria, Controle e Método de análise, 1 ed., 272 p, Rio de Janeiro, Elsevier, 2014.

[14] HECK,L, C., Avaliação da eficiência de inibidores de corrosão em solução salina, Monografia, Universidade do Extremo Sul Catarinense, Criciúma, SC, Brasil, 2014.

[15] OKENIYI, J.O., OMOTOSHO, A.O., AJAYI, O.O., et al.,"Effect of potassium-chromate and sodiumnitrite on concrete steel-rebar degradation in sulphate and saline media",Construction and Building Materials, v. 50, pp. 448-456, 2014.

[16] RAKANTA, E., ZAFEIROPOULOU, T., BATIS, G., "Corrosion protection of steel with DMEA-based organic inhibitor", Construction and Building Materials, v. 44, pp. 507-513, 2013.

[17] PEREIRA, B.R., Avaliação da eficiência de inibidores de tungstato de sódio e de molibdato de sódio em solução salina utilizando barras metálicas, Monografia, Universidade do Extremo Sul Catarinense, Criciúma, SC, Brasil, 2014. 